\title{
Pituitary Apoplexy after Subtotal Thyroidectomy in an Acromegalic Patient with a Large Goiter
}

\author{
Kazunobu Kato, Masakazu Nobori*, Yoshihiro MiYauchi, Motoki Ohnisi, \\ Shyoji Yoshida, Shigeru OYa**, Shin Tomita** and Tomoshige Kino***
}

\begin{abstract}
A case of pituitary apoplexy occurring after subtotal thyroidectomy in an acromegalic woman with a large adenomatous goiter is described. The patient had severe apnea because the large goiter was causing airway compression. Prior to the planned hypophysectomy, a subtotal thyroidectomy was performed to relieve tracheal stenosis. Shortly after the operation, the patient developed a headache that lasted for several days. The serum levels of growth hormone and somatomedin-C spontaneously normalized seventeen days after this episode and have remained normal for two years. Pituitary apoplexy was thought to have caused the observed results without deterioration of the pituitary function.
\end{abstract}

(Internal Medicine 35: 472-477, 1996)

Key words: acromegaly, thyroid goiter, airway obstruction, diabetes mellitus

\section{Introduction}

Pituitary apoplexy is an uncommon event, sometimes fatal, but sometimes it induces complete reversal of acromegaly. It occurs in various situations, such as during the course of drug therapy for pituitary adenoma, during pregnancy, or after cholecystectomy. However, there are no reports documenting pituitary apoplexy after thyroidectomy. In the present case, the serum levels of growth hormone $(\mathrm{GH})$ and somatomedin-C decreased to normal ranges and diabetes mellitus disappeared soon after thyroidectomy. At first the possibility that a GH-or growth hormone-releasing hormone (GHRH)-producing tumor might be hidden in the resected thyroid was considered due to the sudden decrease in the serum GH level following thyroidectomy. But the final diagnosis after examination of the thyroid was classical acromegaly based on the presence of a pituitary $\mathrm{GH}$-producing adenoma.

\section{Case Report}

On August 1, 1991, a 38-year-old female was admitted to Asahi General Hospital. She had been well until ten years earlier when her menstrual periods stopped at the age of 28 years. In 1987, a neck mass that she had first noted in 1986 became enlarged. Then, she suffered from nocturnal dyspnea and noticed enlargement of her hands. In February 1991, thirst and general fatigue developed and she consulted a local physician and was found to have diabetes mellitus and an abnormal mass adjacent to the right side of the trachea, according to chest $\mathrm{X}$-ray films. The patient, an unmarried desk clerk, was referred to us, with the complaint of dyspnea that was more severe lying down than in the sitting position. She had excessive nocturnal snoring and daytime somnolence. Physical examination revealed the following: body temperature, $36.3^{\circ} \mathrm{C}$; pulse rate, 72 per minute; blood pressure, $170 / 120 \mathrm{mmHg}$; height, $153 \mathrm{~cm}$; and weight, $54 \mathrm{~kg}$. Remarkable inspiratory stridor was audible. Neurological examination revealed intact visual fields and no disturbance of cranial or peripheral nerves. The patient had acromegalic features including an increase in soft tissue mass in the hands and feet, periorbital swelling, macroglossia and a prognathic jaw. Both lobes and the isthmus of the thyroid were markedly enlarged. An echogram of the neck showed a large diffuse goiter with multiple cysts. Radiographs and a CT scan of the chest (Fig. 1) disclosed a retrosternal part of the right thyroid lobe compressing the upper airway. A sagittal magnetic resonance (MR) image illustrated another stenotic portion of the airway at the oropharynx. Bronchoscopy confirmed these two stenotic lesions. Spirometry revealed increases in total lung capacity ( $116.9 \%$ of predicted), vital capacity $(118.5 \%$ of predicted) and residual volume ( $117.0 \%$ of predicted) on sit-

From the Departments of Internal Medicine, *Surgery and **Neurosurgery, Asahi General Hospital, Chiba, ***the Second Department of Internal Medicine, School of Medicine, Chiba University, Chiba

Received for publication May 30, 1995; Accepted for publication April 4, 1996

Reprint requests should be addressed to Dr. Kazunobu Kato, the First Department of Internal Medicine, School of Medicine, Yokohama City University, 3-9 Fukuura, Kanazawa-ku, Yokohama 236 




Figure 1. Axial contrast-enhanced CT scan showing a large thyroid goiter constricting the trachea.

ting. These values fell to $79.5 \%, 81.8 \%$ and $79.4 \%$, respectively, when the patient was lying down. A skull X-ray demonstrated a double floor and ballooning of the sella turcica. The MR image showed a pituitary tumor growing inferiorly, destroying the sella floor, extending to the sphenoid sinus and containing a low-intensity lesion (Fig. 2A). Cerebral angiography confirmed the absence of aneurysms around the sella turcica. Laboratory findings showed remarkably elevated GH and somatomedin-C levels associated with severe glucose intolerance (Table 1). The GH response to thyrotropin-releasing hormone (TRH) was paradoxical (Table 2). Injection of luteinizing hormone-stimulating hormone ( $\mathrm{LH}-\mathrm{RH}$ ) elicited an increase in the serum GH level. The serum thyrotropin (TSH) concentration was suppressed and did not respond to TRH. The serum luteinizing hormone (LH) level did not respond and serum follicle-stimulating hormone (FSH) only slightly responded to LH-RH. Serum carcinoembryonic antigen was slightly elevated and the calcitonin level was within the normal range.

Acromegaly was diagnosed, with associated pituitary adenoma, non-functioning adenomatous goiter with multiple cysts, hypertension, diabetes mellitus and secondary amenorrhea. Hypertension and glucose intolerance were resistant to antihypertensive medicines and insulin therapy, respectively. Bromocriptine was ineffective in controlling GH hypersecretion and we planned a hypophysectomy. However, the goiter severely constricted the upper airway and the patient's apnea worsened. Therefore, we performed a subtotal thyroidectomy under general anesthesia on October 2 as a first step in order to relieve the tracheal stenosis before the planned hypophysectomy. The trachea was narrow and intubation was accomplished with the use of a fiberscope. The excised thyroid was $530 \mathrm{~g}$ in weight. Relief of the tracheal compression was confirmed by fiberscopic observation immediately after the operation. Seven hours later, the patient began to complain of a slight headache. On October 5, the headache worsened and she

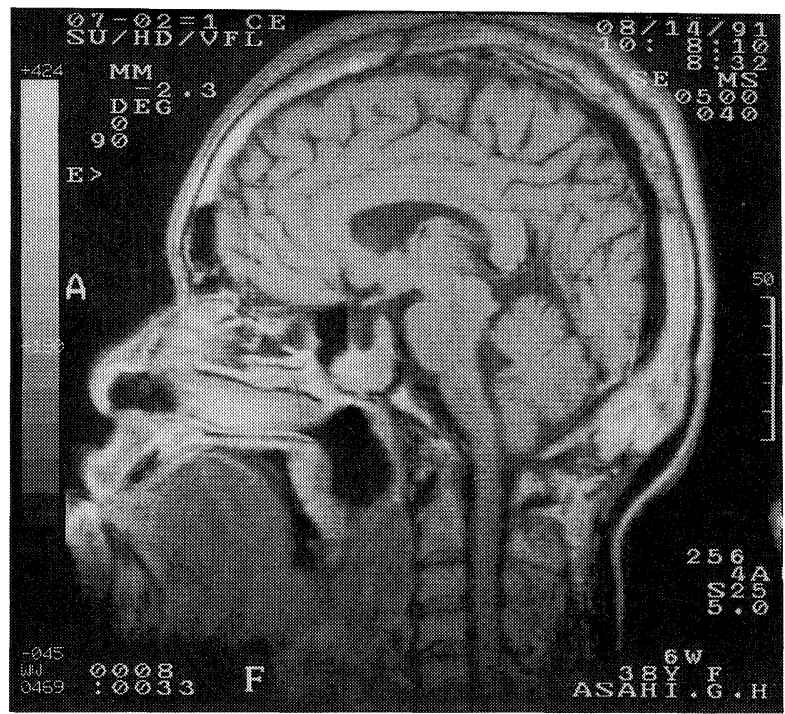

A

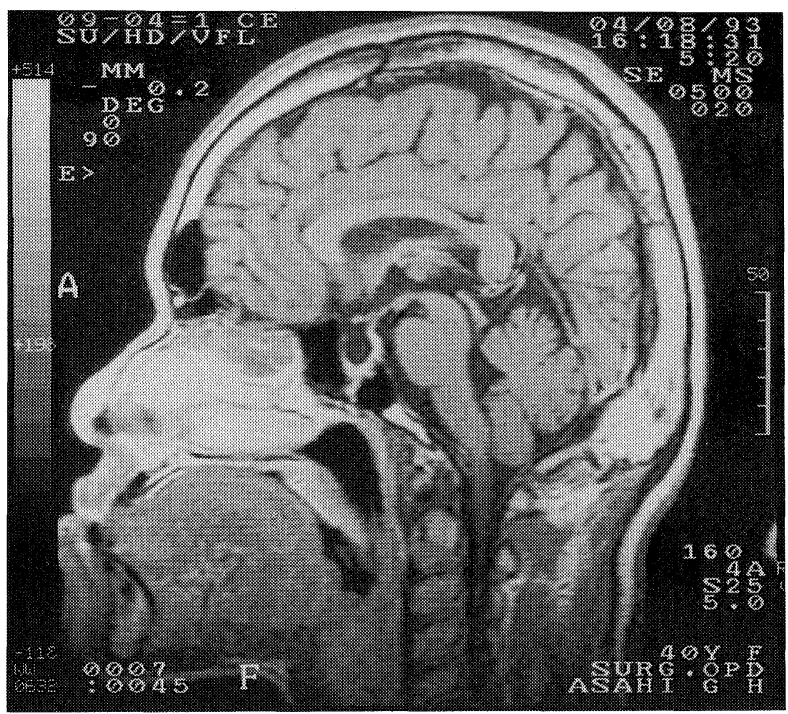

B

Figure 2. Sagittal contrast T1-weighted MR images on admission (A), and twenty months after pituitary apoplexy (B).

complained of diplopia on the next day. On October 10, eyelid ptosis on the left side became apparent. Vomiting and other signs of meningeal irritation were absent and the patient was alert. However, her neck gradually became swollen and apnea developed again. An emergency tracheotomy was performed and a large seroma around the neck was removed; the patient's dyspnea was relieved immediately thereafter; and headache, diplopia and left-sided eyelid ptosis gradually subsided. Nonenhanced serial CT scans taken during the postoperative period showed no evidence of pituitary hemorrhage or subarachnoidal bleeding. Quite unexpectedly, the serum GH and somatomedinC levels decreased to within normal ranges by the 17th postoperative day (Fig. 3). With the hormonal improvement, hyper- 
KATO et al

Table 1. Endocrine Data before and after Thyroidectomy

\begin{tabular}{|c|c|c|c|}
\hline & $\begin{array}{c}\text { before } \\
\text { thyroidectomy } \\
\text { (August } 8,1991 \text { ) }\end{array}$ & $\begin{array}{c}43 \text { days } \\
\text { after thyroidectomy } \\
\text { (November } 20,1991 \text { ) }\end{array}$ & $\begin{array}{l}18 \text { months } \\
\text { after thyroidectomy } \\
\text { (April 5, 1993) }\end{array}$ \\
\hline Growth hormone (ng/ml) & 120 & 2 & 5 \\
\hline Somatomedin-C (U/ml) & 6.16 & 1.05 & 1.29 \\
\hline Thyrotropin $(\mu \mathrm{U} / \mathrm{ml})$ & $<0.03$ & 2 & 1.1 \\
\hline Adrenocorticotropic hormone (pg/ml) & 57 & n.d. & 56 \\
\hline Luteinizing hormone $(\mathrm{mIU} / \mathrm{ml})$ & 0.5 & 2.4 & 6.0 \\
\hline Follicle-stimulating hormone (IU/ml) & 0.5 & 6.6 & 6.2 \\
\hline Thyroxine $(\mu \mathrm{g} / \mathrm{dl})$ & 10.1 & 5.7 & 6.1 \\
\hline Free thyroxine (ng/dl) & 1.6 & 0.8 & 0.8 \\
\hline Triiodothyronine (ng/ml) & 0.9 & 0.7 & 0.8 \\
\hline Free triiodothyronine $(\mathrm{pg} / \mathrm{ml})$ & 4.9 & 8.7 & 3.4 \\
\hline \multicolumn{4}{|l|}{ Thyrotropin-binding inhibitory } \\
\hline immunoglobulin $(\%)$ & 5.6 & n.d. & 0.8 \\
\hline Thyroid-stimulating antibody $(\mu \mathrm{U} / \mathrm{ml})$ & 0.3 & n.d. & n.d. \\
\hline Thyroid-stimulating blocking antibody (\%) & -15.5 & n.d. & n.d. \\
\hline Thyroglobulin (ng/ml) & 530 & n.d. & n.d. \\
\hline Calcitonin (pg/ml) & 12 & n.d. & n.d. \\
\hline Cortisol ( $\mu \mathrm{g} / \mathrm{dl})$ & 12.3 & 15.4 & 19.4 \\
\hline Prolactin (ng/ml) & 16 & 6.1 & 13 \\
\hline Estradiol (pg/ml) & 23.2 & n.d. & n.d. \\
\hline Progesterone (ng/ml) & $<0.2$ & n.d. & n.d. \\
\hline Fasting plasma glucose $(\mathrm{mg} / \mathrm{ml})$ & 275 & 108 & 99 \\
\hline HbA1c $(\%)$ & 14.6 & n.d. & 5.2 \\
\hline Insulin $(\mu \mathrm{U} / \mathrm{ml})$ & 39 & n.d. & 3.5 \\
\hline
\end{tabular}

n.d.: not done.

tension improved and diabetes mellitus completely disappeared. Therefore, insulin therapy became unnecessary. Histological examination of the excised thyroid revealed adenomatous nodular goiter and no malignancy. Immunohistochemical staining of thyroid tissue for calcitonin, GHRH and GH was negative. The load test on the 43rd day after thyroidectomy showed that the paradoxical GH response to TRH remained but the TSH response to TRH and the LH response to LH-RH had recovered (Table 2). On December 3, the patient was discharged without neurological sequelae. The serum levels of $\mathrm{GH}$ and somatomedin-C have remained normal and the patient has had no breathing difficulty during the past two years. An MR image taken 18 months after the thyroidectomy showed empty sella and a remarkable decrease in the size of the pituitary mass (Fig. 2B). Neither hypopituitarism nor hypothyroidism occurred (Table 1). Endocrine replacement therapy has not been necessary. Daytime somnolence and excessive snoring have ceased and menstruation has recovered, although it is irregular.

\section{Discussion}

It is well known that in acromegaly, once serum GH levels are reduced by certain treatments, diabetes mellitus improves and serum somatomedin-C levels also decrease, because $\mathrm{GH}$ antagonizes insulin action and stimulates somatomedin-C pro- duction $(1,2)$. However, there have been no reports, to our knowledge, demonstrating a fall in $\mathrm{GH}$ levels after thyroidectomy. Several possibilities may explain the favorable results in this patient.

The first possibility is that the thyroid might have produced $\mathrm{GH}$. This is the least likely possibility because immunoreactive GH staining of the goiter was negative and because the resected thyroid tissue was not neoplastic but an adenomatous goiter. Some malignant tissues are said to contain immunoreactive $\mathrm{GH}$ in high concentrations. For example, immunoreactive $\mathrm{GH}$ has also been detected in extracts of lung adenocarcinoma and breast cancer $(3,4)$. But an adenomatous goiter would not secrete hormones other than thyroid hormone and calcitonin. Thus, it was not possible for the thyroid to produce ectopic GH.

The second possibility is that the thyroid goiter might have produced ectopic GHRH. This hormone is reported to be secreted by pancreatic, pulmonary and intestinal endocrine tumors and by sympathetic neuronal tumors $(5,6)$. Some medullary carcinomas of the thyroid may contain immunoreactive GHRH tissue $(7,8)$. In the present case, the resected thyroid tissue did not contain a medullary carcinoma. Moreover, immunoreactive staining of thyroid tissue was negative for GHRH by the procedure of Sano et al (9). Regrettably, we did not measure preoperative plasma levels of GHRH in our case.

The final and most likely possibility is pituitary apoplexy, 
Pituitary Apoplexy after Thyroidectomy

Table 2.

Growth hormone (GH) and thyrotropin (TSH) response to $500 \mu \mathrm{g}$ thyrotropin-releasing hormone (TRH) administration before and after thyroidectomy

\begin{tabular}{llrrrrr}
\hline & & \multicolumn{5}{c}{ Respone time (min) } \\
& & 0 & 30 & 60 & 90 & 120 \\
\hline $\begin{array}{l}\text { before thyroidectomy } \\
\text { (August 21, 1991) }\end{array}$ & $\mathrm{GH}(\mathrm{ng} / \mathrm{ml})$ & 130 & 290 & 200 & 170 & 180 \\
& $\mathrm{TSH}(\mu \mathrm{U} / \mathrm{ml})$ & 0.07 & 0.03 & $0.33<0.03$ & 0.04 \\
& & & & & & \\
after thyroidectomy & $\mathrm{GH}(\mathrm{ng} / \mathrm{ml})$ & 2.2 & 5.9 & 3.8 & 3.5 & 3.2 \\
(November 26, 1991) & $\mathrm{TSH}(\mu \mathrm{U} / \mathrm{ml})$ & 2.0 & 7.5 & 6.6 & 4.8 & 4.0 \\
\hline
\end{tabular}

Growth hormone (GH), follicle-stimulating hormone (FSH) and luteinizing hormone $(\mathrm{LH})$ response to $100 \mu \mathrm{g}$ luteinizing hormone-stimulating hormone (LH-RH) administration before and after thyroidectomy

\begin{tabular}{llrrrrr}
\hline & & \multicolumn{7}{c}{ Respone time (min) } \\
& & 0 & 30 & 60 & 90 & 120 \\
\hline before thyroidectomy & GH (ng/ml) & 160 & 180 & 200 & 200 & 210 \\
(August 22, 1991) & FSH (mIU/ml) & 0.7 & 3.4 & 4.7 & 5.0 & 5.1 \\
& $\mathrm{LH}(\mathrm{mIU} / \mathrm{ml})$ & $<0.5$ & $<0.5$ & $<0.5$ & $<0.5$ & $<0.5$ \\
& & & & & & \\
after thyroidectomy & $\mathrm{GH}(\mathrm{ng} / \mathrm{ml})$ & 1.7 & 2.3 & 2.6 & 2.7 & 2.6 \\
(November 25, 1991) & $\mathrm{FSH}(\mathrm{mIU} / \mathrm{ml})$ & 8.6 & 11.0 & 12.0 & 12.0 & 12.0 \\
& $\mathrm{LH}(\mathrm{mIU} / \mathrm{ml})$ & 2.6 & 6.6 & 6.4 & 6.3 & 5.9 \\
\hline
\end{tabular}

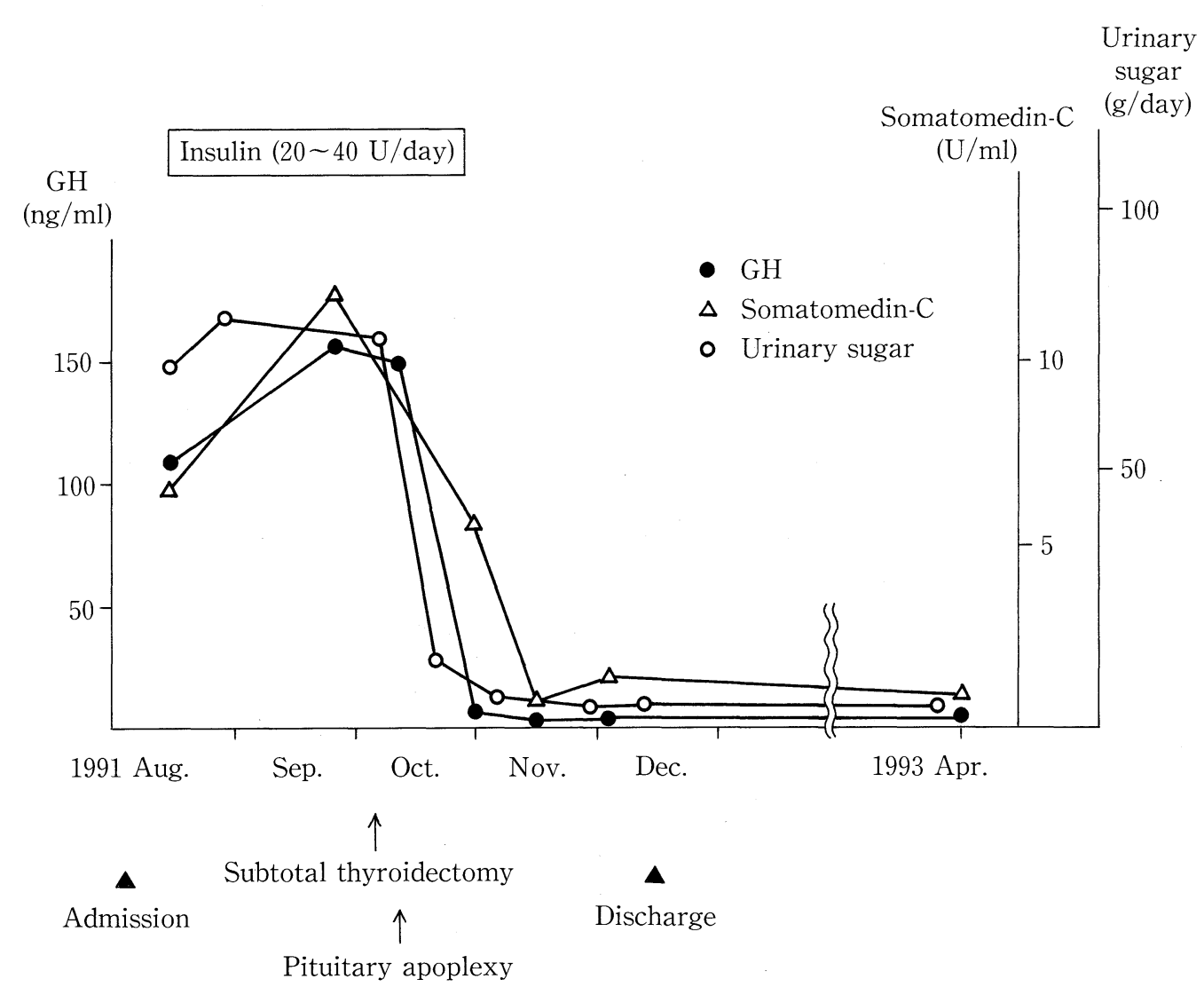

Figure 3. The normalization of growth hormone (GH) and somatomedin-C levels after pituitary apoplexy. 


\section{KATO et al}

occurring soon after the subtotal thyroidectomy. The serum GH level dropped to $6.1 \mathrm{ng} / \mathrm{ml}$ on the 13th post-thyroidectomy day, and it took 17 days for serum GH levels to normalize completely. The patient experienced sudden onset of headache and eyelid ptosis during this period. All of these clinical and neurological features disappeared soon afterwards. These observations strongly suggest that pituitary apoplexy had occurred at this time, although serial head CT scans did not detect any definite changes around the pituitary. Hemorrhagic infarction or ischemic necrosis may have occurred. Impaction of the enlarged tumor at the diaphragmatic notch might have impaired the infundibular circulation, and caused ischemic necrosis of the anterior lobe of the pituitary gland and the subsequent transient neurological features.

In this case, it is difficult to define the trigger for pituitary apoplexy. But the large retrosternal goiter affected the clinical course. Concerning thyroid function, some endocrinological changes occurred before and after the thyroidectomy. Before thyroidectomy, the serum TSH level was suppressed and did not respond to TRH stimulation (Tables 1 and 2). These endocrinological abnormalities are sometimes observed in acromegalic patients $(10,11)$. They may be interpreted as follows. First, the GH-producing adenoma may have expanded and directly oppressed the normal pituitary tissue. Second, latent thyrotoxicosis may have controlled the serum TRH level. Finally, GH may have had a stimulatory effect on thyroid secretion and the serum TSH level may have been suppressed despite euthyroid conditions (12). After the thyroidectomy, the serum TSH level recovered and the response to TRH was restored. Normalization of the serum TSH level may have resulted from the disappearance of the above-mentioned factors. But the direct trigger may have been a mechanical effect of the thyroid goiter on the respiratory function. The patient had severe constriction of the upper airway due to the retrosternal goiter, which produced severe respiratory distress. In this case, the excision of the large goiter caused the following conditions: transient hypoxygenation during the difficult intubation; blood pressure changes or mechanical ventilation during general anesthesia; or sudden improvement in carbon dioxide partial pressure after relief of the upper airway constriction. These factors may have triggered the pituitary apoplexy. To date, rather diverse predisposing factors for pituitary apoplexy have been reported, such as administration of bromocriptine or other somatomedin analogues $(13,14)$, radiation therapy $(15)$, diabetes mellitus (16), surgical stress such as artery bypass surgery (17), cholecystectomy (18); spontaneous pituitary apoplexy has also been described (19). Some of these may have been involved in our case. In addition to these factors, respiratory distress produced by a large retrosternal goiter predisposed the patient to pituitary apoplexy.

Pituitary apoplexy can lead to hypopituitarism and endocrine replacement therapy is sometimes indispensable. But in our case, pituitary, thyroid or adrenal insufficiency did not occur after the pituitary apoplexy. Both the TSH response to $\mathrm{TRH}$, and the LH response to LH-RH recovered just 43 days after the pituitary apoplexy. The serum levels of TSH, LH, FSH and ACTH were within normal ranges 18 months later (Table 1). Accompanying the restoration of these gonadotropic hormones, menstruation recovered, although irregularly. There are also several reports in addition to our case that demonstrate selective reduction in plasma $\mathrm{GH}$ with the preservation of other pituitary functions $(19,20)$. The follow-up MR image obtained 18 months later in our case demonstrated an empty sella turcica and an obvious reduction in adenoma size. Empty sella turcica usually follows spontaneous regression of acromegaly $(1,21$, 22). Finally, patients with acromegaly and an episode of pituitary apoplexy with subsequent inactive disease should be followed for the possibility of recurrence of active acromegaly, because such cases seem to be extremely rarely in the literature $(20,23)$.

Acknowledgements: We thank Dr. Yoshimasa Shishiba of Toranomon Hospital for kind advice and Dr. Hiroshi Matushita of Toranomon Hospital for GHRH staining of the adenomatous goiter.

\section{References}

1) Petersen $P$, Lindholm J. Pituitary apoplexy, the Houssay phenomenon, and accelerated proliferative retinopathy. Am J Med 79: 385, 1985.

2) Melmed SMB. Acromegaly. N Engl J Med 322: 966, 1990.

3) Kaganowicz A, Farkouh NH, Frantz AG, Blaustein AU. Ectopic human growth hormone in ovaries and breast cancer. J Clin Endocrinol Metab 48: 5,1979 .

4) Sparagana M, Phillips G, Hoffmann C, Kucera L. Ectopic growth hormone syndrome associated with lung cancer. Metabolism 20: 730, 1971.

5) Melmed SMB, Ezrin C, Kovacs K, Goodman RS, Frohman LA. Acromegaly due to secretion of growth hormone by an ectopic pancreatic isletcell tumor. N Engl J Med 312: 9, 1985.

6) Barkan AL, Shenker Y, Grekin RJ, Vale WW. Acromegaly from ectopic growth hormone-releasing hormone secretion by a malignant carcinoid tumor. Successful treatment with long-acting somatostatin analogue SMS 201-995. Cancer 61: 221, 1988.

7) Sano T, Asa SL, Kovacs K. Growth hormone-releasing hormone-producing tumors: clinical, biochemical, and morphological manifestations. Endocr Rev 9: 357, 1988.

8) Christofides ND, Stephanou A, Suzuki H, Yiangou Y, Bloom SR. Distribution of immunoreactive growth hormone-releasing hormone in the human brain and intestine and its production by tumors. J Clin Endocrinol Metab 59: 747, 1984.

9) Sano T, Yamasaki R, Saito H, et al. Growth hormone-releasing hormone (GHRH)-secreting pancreatic tumor in a patient with multiple endocrine neoplasia type I. Am J Surg Pathol 11: 810, 1987.

10) Lamberg BA, Pelkonen R, Aro A, Grahne B. Thyroid function in acromegaly before and after transsphenoidal hypophysectomy followed by cryoapplication. Acta Endocrinol (Copenh) 82: 254, 1976.

11) Geelhoed-Duijvestijn PH, Bussemaker JK, Roelfsema F. Changes in basal and stimulated TSH and other parameters of thyroid function in acromegaly after transsphenoidal surgery. Acta Endocrinol (Copenh) 121: $207,1989$.

12) Yoshinari M, Tokuyama T, Kuroda T, et al. Preserved thyroid secretion of thyroxine in acromegalic patients with suppressed hypophyseal secretion of thyrotropin. Clin Endocrinol (Oxf) 36: 355, 1992.

13) Wakai S, Fukushima T, Teramoto A, Sano K. Pituitary apoplexy: its incidence and clinical significance. J Neurosurg 55: 187, 1981.

14) Landolt AM, Froesch ER, König MP. Spontaneous postoperative normalization of growth hormone levels in two patients with acromegaly not cured by transsphenoidal surgery. Neurosurgery 23: 634, 1988.

15) Mohr G, Hardy J. Hemorrhage, necrosis, and apoplexy in pituitary adenomas. Surg Neurol 18: 181, 1982.

16) Cardoso ER, Peterson EW. Pituitary apoplexy: a review. Neurosurgery 


\section{Pituitary Apoplexy after Thyroidectomy}

14: 363, 1984.

17) Shapiro LM. Pituitary apoplexy following coronary artery bypass surgery. J Surg Oncol 44: 66, 1990.

18) Yahagi N, Nishikawa A, Matsui S, Komoda Y, Sai Y, Amakata Y. Pituitary apoplexy following cholecystectomy. Anaesthesia 47: 234, 1992.

19) Rigolosi RS, Schwartz E, Glick SM. Occurrence of growth-hormone deficiency in acromegaly as a result of pituitary apoplexy. N Engl J Med 279: $362,1968$.
20) Dunn PJ, Donald RA, Espiner EA. Regression of acromegaly following pituitary apoplexy. Aust N Z J Med 5: 369, 1975.

21) Login I, Santen RJ. Empty sella syndrome. Sequela of the spontaneous remission of acromegaly. Arch Intern Med 135: 1519, 1975.

22) Bjerre $P$, Lindholm J, Videbaek $H$. The spontaneous course of pituitary adenomas and occurrence of an empty sella in untreated acromegaly. $\mathrm{J}$ Clin Endocrinol Metab 63: 287, 1986.

23) Werner PL, Shah JH, Kukreja SC, Miller SM, Williams GA. Recurrence of acromegaly after pituitary apoplexy. JAMA 247: 2816, 1982. 